Instituto Internacional de Investigación y Desarrollo Tecnológico Educativo INDTEC, C.A.

DOI: https://doi.org/10.29394/scientific.issn.2542-2987.2016.1.2.14.234-253

OAI-PMH: http://www.indteca.com/ojs/index.php/Revista Scientific/oai

\title{
Historia y Pedagogía. La Imagen de la Infancia a Través del Método Biográfico
}

Autora: Martha del Carmen Urquiola

Universidad Fermín Toro, UFT

urquiola.martha@gmail.com

Barinas, Venezuela

\section{Resumen}

La atención en la primera infancia es y será uno de los temas que más debate ha provocado en el correr del tiempo, en su dimensión de la historia es un hecho parcelario poco profundizado. El presente artículo tiene como objetivo a través de textos literarios reconstruir la historia de la atención infantil Venezolana. Metodológicamente el estudio se inserta en el paradigma cualitativo, lo que permitirá la comprensión de los fenómenos, interpretando el pensamiento de autores y de teorías que le rigen. El proceso se apoyó en una investigación teórica, con una finalidad netamente documental, enfatizada en el diseño bibliográfico-narrativo mediante la aplicación del método hermenéutico y dialéctico. Se empleó sólo medios impresos, se recurrió al arqueo de fuentes bibliográficas, selección de las fuentes más relevantes, validación, lecturas detalladas, localización, fichaje, codificación, interpretación, redacción y construcción teórica, a partir de la categorización y comparación. Surge como resultado necesario, reconstituir el objeto de la infancia, no sólo por la constitución de nuevas respuestas, sino también por el desafío para las nuevas investigaciones en las que deben existir infancias capaces de hablar por sí mismas, de ser protagonistas y narradoras de su propio relato. biográfico.

Palabras clave: historia; pedagogía; imagen; infancia; método; 


\title{
History and Pedagogy. The Image of Children Through the Method Biography
}

\begin{abstract}
Attention in early childhood is and will be one of the issues that most debate has resulted in over time, in its dimension of the story is a little parcel done deepened. This article aims through literary texts to reconstruct the history of the Venezuelan child care. Methodologically the study is inserted into the qualitative paradigm, enabling the understanding of the phenomena, interpreting the thought of authors and theories that govern it. The process was based on a theoretical research, with a purely documentary purpose, emphasized in the literature-narrative design by applying the hermeneutic and dialectical method. only print media was used, it was used to tonnage of bibliographical sources, selection of the most relevant sources, validation, detailed readings, location, signing, coding, interpretation, writing and theoretical construction from the categorization and comparison. Arises as a result necessary to reconstitute the object of childhood, not only for the creation of new responses, but also the challenge for new research that should be childhoods able to speak for themselves, to be protagonists and narrators of their story itself.
\end{abstract}

Keywords: history; education; image; children; method; biography.

Date Received: $16-08-2016$

Date Acceptance: 15-09-2016 


\section{Introducción}

Desde el inicio de los tiempos la educación ha sido considerada como elemental en la formación del individuo, pues contribuye a su formación consciente y sienta las bases necesarias para su aprendizaje a lo largo de toda la vida, hoy en día la educación es vista desde una perspectiva más amplia pues debe servir para vivir en un planeta bajo presión. El mundo está cambiando y por ende la educación debe cambiar. Ahora bien, esta cosmovisión me permite reflexionar de manera ambiciosa sobre la escuela; teniendo como objeto de estudio, el niño.

Si bien en la actualidad el termino niñez resulta casi emblemático la actual manera de concebir al niño, no existió desde siempre para ello se utilizará como punto de partida los estudios de Philippe Ariés (1987) en su obra El Niño y la Vida Familiar en el Antiguo Régimen, historiador europeo, quien aporta uno de los estudios históricos más importantes, aunque también controvertido por haberse ceñido en su estudio a una limitada parte de la sociedad francesa carente de representatividad proveniente de hogares instruidos se han desarrollado una serie de trabajos que toman como objeto de estudio a los menores, algo sin precedentes ya que la presencia de los menores en la historia se limitaba a ser una estadística más.

No obstante, esta primera etapa de la vida ha sido atendida de forma muy dispar y, además, el origen de su interés es bastante reciente en la historia de los países desarrollados, este camino recorrido ha tardado varios años en llegar a consolidarse pese al trabajo de pedagogos de todas las épocas que vislumbraron la importancia de la atención recibida desde el inicio de la vida. Con respecto a la utilidad del estudio puede ser considerado un aporte teórico e histórico que sirve para identificar la conformación y evolución de la educación inicial venezolana por lo tanto se aspira dar a conocer aquellos componentes históricos que no han sido profundizados anteriormente, como es el proceso de conformación de la atención temprana modelos pedagógicos 
utilizados, fracturas y discontinuidades dadas en este transitar histórico. Es decir, esta investigación busca responder algunas interrogantes sobre el surgimiento del primer nivel educativo en el país y por lo tanto llenar un vacío intelectual y académico.

La propuesta investigativa consiste en establecer desde la perspectiva histórica estrategias que permitan la obtención de datos, para dar cuenta de las diversas concepciones, factores y procesos que se llevaron a cabo para que la educación inicial se haya consolidado en el país. Con la clara intención de relacionar e identificar al fenómeno educativo y sus necesidades dentro de las distintas realidades del país. Así como también la construcción de un saber histórico real e integral de esta primera etapa educativa.

\section{Retrospectiva Histórica}

Diversidad de autores coinciden en afirmar que no se puede hablar de educación infantil o preescolar propiamente dicha hasta que no se produce la gestación de los sistemas de educación por su puesto una vez iniciada el camino de estos pasaran años en conseguir un grado importante en el primer nivel del sistema educativo. Anterior a su institucionalización han existido precedentes teóricos pedagógicos que han, considerado la importancia de la educación del niño menor de seis años, como preparación para la escuela.

Estos primeros precedentes teóricos a los cuales me referiré, provienen de la cultura occidental, en la Grecia clásica el gran filósofo Aristóteles (484322 a.C.) índico la necesidad de una educación basada en el juego como actividad física necesaria a la cual llamo primera edad (Colmenar, 1995, pág. 4). Las orientaciones anteriores quedaran presentes en los postulados pedagógicos posteriores. Los griegos tenían una visión universal, eran educados por medio de los textos de Homero, se buscaba el conocimiento de la verdad, de lo bello y del bien. Platón soñaba con una república ampliamente 
democrática donde la educación tenía un papel fundamental, la educación debía ser pública.

Otra figura importante de la antigüedad clásica Favio Quintiliano expreso su ideología afirmando la necesidad de un aprendizaje formal para los niños menores de siete años (García, 1986. pág. 48). Para los siglos XV, XVI, estas ideas seguían presentes sin que existieran instituciones concretas que reflejaran una práctica real de estos principios. Al realizar este análisis retrospectivo, adquiere especial relevancia Juan Amos Comenio quien recalco por primera vez el concepto de escuela materna indicando un marco de aprendizaje situado en el seno familiar.

Igualmente, en el siglo XVIII, Jean Rousseau iluminado por la ilustración público en 1762, una de sus obras que inicia una nueva conceptualización sobre la infancia. En Emilio se manifiesta que el niño, no es un hombre en pequeño, que la infancia tiene sus formas de ser, de pensar y de sentir. La educación en Emilio empieza en los primeros días y se constituye en ordenados estadios. Aflora claramente la pedagogía en la educación inicial a través de los postulados de Rousseau, basada en la evolución psicológica y física del niño. Emerge una profunda transformación de las creencias y de las estructuras mentales.

Esta brizna en el tiempo, obliga a precisar que el niño y la niña desde el nacimiento hasta los siete años, ha sido objeto de preocupación y análisis de estudio por grandes pedagogos y filósofos. Sin embargo, aún se encuentra enclaustrada solamente en ideas. Es hacia la mitad del siglo XVIII, cuando se pone en práctica la operatividad de dichas ideas.

En Europa se originan los primeros ensayos prácticos de atención al infante, como una separación del niño del recinto hogareño. Las primeras instituciones que surgen como intento de atención del infante son las dame schools, inglesas los asilos alemanes y las escuelas de juego holandesas, así como las creadas por Oberlin (1770). Para contribuir a su acción educativa se 
ocupó de la formación de maestras infantiles a quienes llamo conductoras de la infancia. Se considera en Oberlin el primer intento serio de educación de párvulos. Se puede apreciar que la historia de la educación de la primera infancia es más antigua que la historia de la educación preescolar.

En Gran Bretaña, tras las experiencias llevadas a cabo por Robert Owen en (1816) motivado por sus ideas abre la primera escuela para los hijos de los trabajadores de su fábrica textil. En la ciudad de New Lanark (Escocia). Ideo un proyecto educativo separando a los alumnos en aulas de clases por edad a partir de los 2 años hasta la edad adulta.

El interés hacia la educación temprana y el cuidado de los niños se considera como el resultado casi inevitable de la primera industrialización que necesito del trabajo de las mujeres sobre todo en fábricas textiles. Las concepciones pedagógicas de Owen se inspiraban en diversas fuentes, pero principalmente en Rousseau. Sanchidrián (2010) expone que en la Infant Schools "se utilizaban diferentes estrategias didácticas, con pequeños bloques de madera los niños aprendían a sumar y restar, con tarjetas ilustradas se les enseñaba a leer y se utilizaban letras de metal del alfabeto” (pág. 1).

\subsection{Primeros acercamientos Contexto Venezolano}

Luque (2011) refiere que la atención temprana en Venezuela se ubica hacia el año 1845, de la mano del Dr. José María Vargas quien se desempeñaba como Presidente de la Dirección de Instrucción Pública, el cual plantea la necesidad de formar al docente así como la creación de escuelas infantiles y asilos, sus ideas sobre todo relacionadas con el abordaje de los problemas sanitarios y sociales de la niñez venezolana impulsan su afán por labrar mejoras en la atención y necesidades de los infantes, pues la concepción del niño, para ese momento, era otra.

Este párrafo introductorio sobre los primeros acercamientos de la atención infantil venezolana me obliga a desentrañar que los primeros intentos 
para el cuidado y atención infantil sentó los cimientos de dos áreas privilegiadas para atender la vulnerabilidad infantil: por un lado, se origina la pediatría de la mano del Dr. José Manuel de los Ríos y se inicia la gestación de la atención infantil hoy educación inicial.

Tras el fin de la Guerra Federal (1863) la devastadora lucha deja un país empobrecido, atrasado en todos los órdenes de la vida nacional, además de la pérdida de innumerables vidas humanas, sin darle la importancia que merecía la educación para esta época. Siguiendo el planteamiento de Fernández (1998) el cual expone: "No se puede esconder que la administración política que asume el gobierno de la República a partir del 27 de abril de 1870 encuentra en gran descuido el sector de la educación pública y ésta yacía en estado de postración" (pág. 9).

La reconstrucción del Estado Venezolano; y las ideas del pensamiento ilustrado acompañan al ideario del liberalismo venezolano que pone énfasis en reafirmar la autoridad política del poder civil frente a la Iglesia Católica. La educación cobra fuerza con el decreto del 27 de junio de 1870 sobre la extensión y gratuidad de la instrucción primaria, resolviéndose con esta decisión el problema que durante cuarenta años mantuvo estrangulada e impidió la marcha regular de la primera instrucción. Esta iniciativa, se debe reconocer a Antonio Leocadio Guzmán.

Hacia el año 1878, se consolida la fundación del asilo de huérfanos de Caracas, sin embargo no fue sino después del terremoto de Cua que se cristalizo el sueño del Licenciado Agustín Aveledo. Emprendedor de esta maravillosa idea, conto con el apoyo de Eduardo Calcaño y promovió por si solo esta obra, pues su idea no fue bien acogida en la sociedad caraqueña, se le atribuyen a Aveledo calificativos como "maestro, prócer de la paz, profesor de la caridad, insigne educador" (Aveledo 2001, pág. 4) entre otros.

Hombre sencillo y modesto, de corazón amplio, conocido por sus maravillosos aportes a la educación venezolana y trabajo en beneficio del 
prójimo, esta insigne figura educativa debe ser rescata de los libros y textos donde se hace mención a su obra, impulsador, creador, director y administrador del primer asilo caraqueño es el máximo representante de los primeros acercamientos a la atención infantil en Venezuela.

Esto sucedió un 24 de julio de 1878 se inaugura el primer orfelinato venezolano en la parroquia La Pastora ubicado en la casa $\mathrm{N}^{\circ} 58$ entre las esquinas de Portillo a Terrero, la inauguración coincide con la fecha de celebración del natalicio de Simón Bolívar y día de San Vicente Paul, el asilo albergaba a niños desamparados y abandonados de ambos sexos en edades comprendidas entre los 3 y 7 años, los varones permanecían hasta los 14 o 15 años y las niñas indefinidamente. Estas instituciones consideradas de tipo caritativo les enseñaban a los niños religión, lectura, escritura y algunas manualidades, cuya tutela estaba a cargo de religiosas (Bravo y Uzcategui: 2013).

Antes de este hecho según refiere el Primer Congreso Pedagógico Venezolano, se estriba que entre las actividades del Congreso se destaca la consideración del tema "Escuelas Infantiles" para ello se presentaron dos trabajos, uno del ponente oficial Miguel Arroyo y otro de Julio Castro. Este último fue enviado en 1874 junto con Mariano Blanco a los Estados Unidos por el Presidente Guzmán Blanco a instruirse en pedagogía por dos años (Luque 2011: pág. 25), ideas que luego implantaría en Venezuela. A mi juicio Julio Castro impulso el realismo pedagogía infantil en Venezuela.

\subsection{De los asilos a la Educación Inicial}

Tomando en consideración que el estudio de la historia requiere una profunda revisión bibliográfica me remito a la Memoria Educativa Venezolana, en su tomo III, describe algunos pasos llevados a cabo para la institucionalización de la educación preescolar., entre los cuales se destacan: 
La educación preescolar se inició tímidamente en Venezuela el 16 de septiembre de 1913, para esa época Felipe Guevara Rojas cumplía funciones de Ministro de Instrucción Pública, se creó en Caracas el primer instituto venezolano de educación preescolar como un anexo a la Escuela Normal de Mujeres "Gran Colombia. A través del enunciado del Artículo $2^{\circ}$ de la Ley de Instrucción Pública (1913), donde se hacía distinción entre las Escuelas Primarias comunes y las de tipo especial a la cual pertenecían los Jardines de Infancia.

De igual forma en el Artículo $5^{\circ}$ de la misma ley se autoriza la creación de los jardines de infancia, así, comienza a funcionar el primer Jardín de Infancia como instituto oficial de Educación Preescolar en Venezuela, con una matrícula de 40 niños (Bravo y Uzcategui: 2013). Luego por decreto el 18 de diciembre de 1920, se instituye la educación preescolar, enseñanza destinada a proporcionar a los niños que no tienen aún la edad escolar, los cuidados que reclaman su desarrollo físico, intelectual y moral.

Para impulsar la educación preescolar, en 1920 el ministro de instrucción pública Dr. Rafael González Rincones, solicito ante el Ministerio de Relaciones Interiores, la donación de terrenos en cada capital de distrito, con el fin de construir locales destinados a Jardines de Infancia y la designación de una partida presupuestaria para su respectivo funcionamiento. Sin embargo esta solicitud no fue considerada y nunca se cumplió.

Afines de 1920, a requerimiento del Ejecutivo, las Municipalidades de la República cedieron una hectárea de terreno en cada Distrito para la edificación de escuelas maternales, se creó para aquel entonces la Escuela Modelo Hermenegilda Gómez donde se dictaron los primeros programas para la enseñanza maternal; una vez concluido su proceso de formación deberían ir a trabajar en otros estados del país, dos años después esta escuela fue clausurada por considerarla ineficaz. 
El establecimiento de la enseñanza maternal en el país es una de las innovaciones introducidas en la legislación escolar. La Escuela Maternal dirigida por un personal técnicamente preparado, consciente de la dedicada misión que está llamando a desempeñar, tiene un efecto importante en la preparación del nuevo contingente escolar. Ella está destinada a asegurar el desarrollo físico, intelectual y moral del niño en la edad preescolar, al mismo tiempo que a evitarle los peligros a que se halla expuesto fuera de la vigilancia del hogar, sobre todo en el seno de las familias numerosas de la clase obrera, a quienes las duras exigencias de la vida cotidiana le impiden ejercer esta acción educadora.

Con el modelo "Hermenegilda Gómez" se hizo el primer ensayo pedagógico en Venezuela destinado a mejorar las condiciones y atención del infante, instalada sin las comodidades exigidas para esta clase de plantel y sin un personal especializado en la materia, los resultados obtenidos no correspondieron, ni siquiera en parte, al patriótico fin para que fue establecida.

Alegando que no había personal especializado para este tipo de institución, mucho menos para la atención de las nuevas escuelas graduadas, la escuela maternal se cerró en el año 1923, a lo que el ministro González señala que es razón insuficiente cuando está era atendida por "dos Hermanas de la Congregación da San José de Tarbes y una maestra con certificado de instrucción primaria elemental.

Sentencia el ministro que esta acción debió ser acogida con más propensión considerando que se había esperado 92 años para introducirla en nuestro sistema escolar. Se procede a estudiar el grave problema de los maestros ya que se requería contar con un buen número de docentes preparados técnicamente para poseer una buena organización del personal docente para este nivel.

En 1970 se crea el Departamento de Educación Preescolar dependiente de la División de Educación Primaria y Excepcional de la Coordinación General 
de Docencia, lo que posibilitó que para el año 1975 fuera creada la Dirección de Educación Preescolar. Esta dirección obtuvo algunos logros significativos, entre ellos: el entrenamiento a maestros aspirantes a ingresar al nivel, cursos de escuela activa a supervisores y maestros en servicio, capacitación de maestros y directivos en servicios, realización de jornadas de estudios del preescolar en Venezuela, así como el incremento de la matrícula por año.

Un momento de gran importancia fue la institucionalización de la Educación Preescolar como nivel del Sistema Educativo Venezolano, hecho que ocurrió en 1980 con la promulgación de la Ley Orgánica de Educación (LOE 1980). Al ser incluirlo como nivel repercute en la relevancia y significación que se le confiere a la educación preescolar. Para 1986, la educación preescolar es enfocada en un currículo humanista, centrado en la necesidades e intereses de los niños y niñas, adquiere importancia y relevancia social y es considera como una necesidad para la formación del futuro adulto de un país; este documento viene a fortalecer los aspectos teóricos, filosóficos, legales y psicológicos, así como la operatividad en las aulas de la rutina diaria.

Con el establecimiento y delimitación de áreas de trabajo, el aula de preescolar se convierte en el laboratorio donde los niños pueden desarrollar todo su potencial creador. Sin embargo, todos estos avances curriculares dejan por fuera aspectos esenciales para lograr la calidad en la educación hacia donde avanzamos.

Con la promulgación de la Constitución de la República Bolivariana de Venezuela (1999), se abre camino a la educación maternal y se establecen dos fases maternal (0-3 años) y preescolar (3-6 años) es así como adquiere el termino educación inicial considerada un sub-sistema del sistema educativo venezolano, haciendo hincapié en la incorporación de la familia y la comunidad como elementos clave para consolidar los aprendizajes del niño y la niña, y, en la atención no convencional una vía de inclusión para los más desasistidos a fin de expandir la cobertura de atención a la infancia. Siguiendo con el 
argumento anterior Delors (1996), manifiesta que la educación debe ser considerada:

Experiencia social a través de la cual el niño se conoce, enriquece sus relaciones y adquiere conocimientos, y debe iniciarse antes de la edad escolar obligatoria, según diferentes formas en función de la situación, pero las familias y las comunidades locales deben involucrarse (pág. 13).

Se resalta entonces que la enseñanza debe empezar desde el hogar, siendo la familia el primer escenario de socialización. La atención no convencional ofrece la posibilidad de atender al niño o la niña en su hogar, acompañado de su grupo familiar, esta incorporación permite la consolidación de la triada (familia, escuela y comunidad), así como la orientación a las madres en gestación.

Continuando con este modelo, se propone la revisión curricular y en el 2005 se oficializa un nuevo currículo centrado en corrientes constructivistas, cambiando las áreas de desarrollo por áreas de aprendizaje; la globalización de los aprendizajes; y la reducción de áreas de trabajo caracterizan este modelo; la educación inicial vive un momento de transformación, y los problemas aún persisten, la escasa atención a los niños y niñas de 0 a 3 años, la poca asignación de recursos financieros y, aunado a esto, el déficit de infraestructuras adecuadas para la atención de los pequeños.

Por otra parte, con la inclusión de los llamados Simoncitos, guiados hasta el 2010 por el Servicio de Protección la Familia y la Infancia (SENIFA), se incorpora matricula a los centros escolares, sobre todo en edad maternal, pues le corresponde al centro de educación, más cercano al simoncito, brindar las orientaciones pedagógicas y administrativas que le permitan un cambio de paradigma en su forma tradicional de funcionar. Con el seguimiento y control a los simoncitos se unifica la atención a la primera infancia en Venezuela, 
siguiendo líneas orientadoras del Ministerio del Poder Popular para la Educación (MPPE).

\subsection{Influencia de las Ideas Frobelianas en la Educación Infantil Venezolana}

Luego de la implantación del primer kindergarten (1840) las ideas pedagógicas de Froebel recorrieron el mundo, en Venezuela esta idea comienza a madurar con la implantación del primer asilo (1878), la educación preescolar inicia los primeros movimientos pedagógicos destinados a beneficiar a los infantes de menos de seis años, los postulados frobelianas inspiraron la atención y el cuidado de los niños de la época.

Guiados por ideas de libertad, movimiento y juego se comenzó a implantar ideas pedagógicas en la atención al infante. Se toma de allí la organización de los espacios destinados a la atención de los pequeños, mediante la colocación de materiales y herramientas, donde el juego libre y espontaneo es permitido. El movimiento moderno propone que la edad óptima para la atención de los infantes es de 3 a 6 años, estos con la compañía de una maestra y una auxiliar, en aulas con un limitado número de niños para una mejor atención.

Actualmente estas ideas se encuentran vigente pues las aulas para la atención pedagógica de los niños están estructuradas por espacios, áreas o rincones según el Fascículo Organización del Ambiente de Aprendizaje (MPPE: 2005). Se mantienen materiales y recursos elaborados de diferentes materiales como cartón, madera, plástico, a los cuales Froebel denomino dones.

En cuanto a la distribución de las docentes para la atención pedagógica cada aula de educación inicial es atendida con una maestra y una auxiliar o dos maestras de educación inicial, con una matrícula de entre 25 y 30 niños para la fase preescolar, y para la fase maternal existen algunas excepciones 
dependiendo de los grupos de niños con que se ubiquen en cada aula, generalmente se distribuye un máximo de 16 niños y niñas por aula.

\section{Metodología}

El estudio se fundamentó en el paradigma cualitativo, que siguiendo las ideas de Martínez (2006) "no se trata, por consiguiente, del estudio de cualidades separadas o separables; se trata, pues, del estudio de un todo integrado que forma o constituye primordialmente una unidad de análisis y que hace que algo sea lo que es..." (pág. 66); es decir, se establecen ciertos criterios que me permitirán analizar el fenómeno como un todo.

Bien lo afirma Ortiz (2008) cuando dice que el paradigma de investigación cualitativa "tiene como base la interpretación, comprensión y entendimiento" (pág. 120); esto permitirá establecer mi punto de vista desde el enfoque sistémico reflexionando sobre los eventos que se integran en un todo, apoyados en la hermenéutica - dialéctica. La investigación cualitativa pretende rescatar lo genuinamente humano de los fenómenos didácticos: los distintos significados, significaciones, motivaciones, percepciones, intenciones de los sujetos. Su conocimiento se construye en la práctica y retorna a ella para esclarecerla.

De igual forma, el estudio propuesto corresponde al método biográficonarrativo entendido como una modalidad de investigación que me permitirá ampliar el conocimiento sobre lo que realmente sucede, a través del punto de vista de los implicados, personas anónimas que aportan, por medio de testimonios escritos, una mirada personal e íntima recuperando su propia voz al hacerla pública.

La investigación biográfica-narrativa se asienta, dentro del giro hermenéutico producido en los años setenta en las ciencias sociales. De la instancia positivista se pasa a una perspectiva interpretativa, en la cual el significado de los actores se convierte en el foco central de la investigación. A 
mi juicio se entenderán los fenómenos sociales como textos, cuyo valor y significado, primariamente, vienen dados por la autointerpretación que los sujetos relatan en primera persona, donde la dimensión temporal y biográfica ocupa una posición central.

El método al que aspiro es un cuerpo conceptual articulado que clarifica y orienta la resolución de los problemas prácticos. Su objeto es iluminar la práctica, dar sentido a lo desconocido y ofrecer instrumentos que permitan una reflexión sistemática. Más que explicar los fenómenos didácticos, los describe y los contextualiza, se abre a la crítica y revisión constante, es democrática y deliberativa. Más que teorías acabadas, promueve procesos de teorización; y más que leyes, busca instrumentos de pensamiento y de acción, se orienta hacia la descripción y comprensión de fenómenos pasados, hacia el análisis del significado de la intersubjetividad humana

En la investigación la fuente principal la constituyeron documentos a ser interpretados, porque de ellos se extrajo los contenidos en función del evento descrito como fenómeno a estudiar, para lo cual, se considera que todo escrito sirva de soporte. Por lo tanto, serán las herramientas en las que la autora me apoye para desarrollar la metodología establecida. Al respecto Teppa (2012) argumenta: "todo tipo de información sirve como testimonio en la investigación cualitativa: imágenes, textos, discursos, videos, grabaciones, sonidos, mapas, datos de frecuencias, fechas, símbolos entre otros. (pág. 32). En consecuencia, empleé para el abordaje del tratamiento, los enfoques teóricos relacionados con las temáticas descritas, el fichaje bibliográfico, de citas textuales, de resumen y mixtas.

Una vez definidos los datos, se pasó al trabajo de campo, la investigación cualitativa opera con datos que son discursos y se expresan en informes, palabras, texto, gráficos e imágenes, esta variedad de recursos se encuentra en estrecha relación con la investigadora. La realidad social es única y dependiente del contexto por eso es única e irrepetible, esta 
requiere que toda la información recolectada se interprete solo en el marco contextual de la situación social estudiada. El proceso de construcción de la realidad se abordó desde la ejecución de cuatro pasos: análisis documental, interpretación, categorización, triangulación y teorización.

\section{Aproximaciones Conclusiva}

Debe asumirse la diferencia generacional de la infancia como referente de su propia identidad, dejando de concebir a los más pequeños como sujetos que deben ser disciplinados y controlados, pues deben ser vistos como actores sociales competentes. Para poder entender las diferentes visiones de la infancia como construcciones de las influencias sociales, resulta fundamental prestar especial atención a ciertos hechos históricos y actuales como factores determinantes e influyentes en la expansión de las políticas y programas específicos dedicados a esta etapa vital y educativa del ser humano

Al profundizar la temática he podido constatar que la bibliografía existente para el estudio es escasa por lo cual afirmo que los estudios historiográficos en el país dirigen la vista hacia grandes presidentes, gobiernos, movimientos revolucionarios y caudillos, dándole énfasis a la visión política de la historia, lamentablemente pocos han sido los escritos de aquellos venezolanos que en épocas anteriores y pese a las muchas dificultades han puesto su corazón y lo mejor de sí, en procura de lograr una mejor educación para aquellos niños que hoy son el presente.

A la luz de lo expuesto hasta ahora se vuelve necesario, en alguna medida, reconstituir el objeto de la infancia, no sólo por la constitución de nuevas respuestas, sino también por el desafío para las nuevas investigaciones en las que deben existir infancias capaces de hablar por sí mismas, de ser protagonistas y narradoras de su propio relato. Elevar dicha voz se torna en una condición indispensable para llevar adelante el discurso moderno que trae consigo la virtud de reconocer que todavía se sabe poco 
sobre lo frágil, poderosa y prometedora que es la naturaleza de la primera infancia.

En la actualidad, la educación infantil y atención de la primera infancia se ha convertido en uno de los objetivos principales en las agendas de las políticas educativas globales de la mayoría de países. De allí la necesidad de atender y educar a los niños y niñas durante la primera infancia ha experimentado un aumento notable de la atención política e institucional durante las últimas décadas, especialmente los últimos años, de modo que tanto los responsables políticos como los expertos han reconocido que un acceso equitativo a una educación y cuidado de calidad durante esta etapa puede reforzar las bases del aprendizaje a lo largo del periodo vital y responder a las amplias necesidades sociales y educativas para todos los niños y sus familias.

\section{Referencias}

Ancheta, A. (2007). La Formación Inicial del Profesorado de Educación Infantil en Italia, Reino Unido y España. Una perspectiva Comparada. Revista Española de Educación Comparada. Número 13, pp. 219-251.

Aries, P. (1987). El Niño y la Vida Familiar e el Antiguo Régimen. Editor OEA.

Aveledo, L. (2001). El licenciado Agustín Aveledo "Prócer de la Paz. Una visión de dos facetas de su vida: la de educador y la de filántropo. Trabajo de Grado Publicado para optar al título de Magister en Historia de Venezuela. Universidad Católica Andrés Bello.

Bravo, L. Uzcategui, R. (2013). "Memoria Educativa Venezolana. Tomo II. UCV. Venezuela.

Bravo, L. Uzcategui, R. (2013). "Memoria Educativa Venezolana. Tomo III. UCV. Venezuela. 
Colmenar, O. (1995). "Génesis de la Educación Infantil en la Sociedad Occidental". Revista Complutense, 6(1),15-30.

Constitución de la República Bolivariana de Venezuela (1999). Gaceta Oficial de la República Bolivariana de Venezuela 36.860 (Extraordinaria), diciembre 30. Venezuela.

Delors, J. (1996). La educación encierra un tesoro. Madrid: Santillana / Unesco ediciones.

Gadotti, M. (1998). Historia de las Ideas Pedagógicas. Siglo XXI Editores.

García, G. (1986). Trayectoria Histórica de la Educación Preescolar. Enciclopedia de la Educación Preescolar. Tomo 7. Madrid: Santillana.

Fernández, R. (1998). La Educación en el siglo XIX. Biblioteca Nacional de Venezuela.

Luque, G. (2011). Venezuela Medio Siglo de Historia Educativa 1951-2001. Ministerio del poder popular para la Educación. (Primera Edición). Venezuela.

Ley Orgánica de Educación (1980). Gaceta Oficial de la República Bolivariana de Venezuela $\mathbf{N}^{\circ} 2635$ (Extraordinario). Julio 28. Venezuela.

Ley Orgánica de Educación (2009). Gaceta Oficial de la República Bolivariana de Venezuela $\mathbf{N}^{\circ} 5929$ (Extraordinario). Agosto 15. Venezuela.

Martínez, M. (2006). Ciencia y arte en la metodología cualitativa. México: Trillas.

Ministerio de Educación y Deportes (2005). Fascículo Ambiente de Aprendizaje. Venezuela.

Observatorio Educativo de Venezuela (2012). Con derechos desde el principio. Semana de Acción Mundial por la Educación (SAME). [Documento en línea]. Recuperado de: 
http://observatorioeducativo.wordpress.com/category/educacionparatodos/

Ortiz, F. (2008). Diccionario de metodología de la investigación científica, (Segunda Edición). México: LIMUSA.

Sanchidrián, C. (2010). La Educación Infantil en Gran Bretaña. Modelos y

Debates. Departamento de Teoría e Historia de la Educación. Universidad de Málaga.

Teppa, S. (2012). Análisis de la información cualitativa y construcción de teorías. Ediciones GEMA. Venezuela.

Uslar, P. (1989). De una a otra Venezuela. Monte Ávila Editores. 


\section{Urquiola Martha del Carmen \\ e-mail: urquiola.martha@gmail.com}

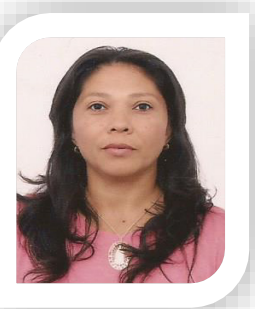

Nacida en Barinas Estado Barinas Cursa estudio de

Doctorado en Ciencias de la Educación en la

Universidad Fermín Toro oficina de enlace Barinas.

Magister Scientiarum en Educación Prescolar de la

Universidad Fermín Toro (2005). Licenciada en

Educación Mención Preescolar Universidad Nacional

Abierta (2000). Actualmente se desempeña como Directora del Centro de Educación Inicial Dr. Arturo Uslar Pietri y profesora en la Universidad Fermín Toro en la Maestría de Educación Inicial. Ha sido tutora y Jurado de trabajos de investigación en las maestrías de Educación Inicial y Gerencia y Liderazgo, facilitadora de varios talleres en el área de planificación y evaluación.

El contenido de este manuscrito se difunde bajo una Licencia de Creative Commons ReconocimientoNoComercial-Compartirlgual 4.0 Internacional 